\title{
Geossistemas do Semiárido Brasileiro: Considerações Iniciais
}

\author{
Geosystems of the Brazilian Semiarid: Initial Considerations
}

\author{
Lucas Costa de Souza Cavalcanti \\ Professor da Universidade Federal de Pernambuco (UFPE) \\ lucascavalcanti3@gmail.com
}

\begin{abstract}
Resumo
O conhecimento integrado das paisagens do semiárido brasileiro encontra abrigo na literatura geográfica pelo menos desde o início do século 20. Contudo, há necessidade de precisar os limites das unidades e ampliar a informação acerca da organização natural das paisagens. Este trabalho teve como objetivo identificar aspectos da estrutura dos geossistemas do semiárido brasileiro. Para tanto, foi confeccionada uma carta de paisagens utilizando ferramentas de geoprocessamento e trabalhos de campo. Os resultados foram correlacionados com propostas já existentes e modelos taxonômicos nacionais e internacionais. Ficou evidente a necessidade de levantamentos sistemáticos dos limites dos geossistemas transicionais e de enclaves, bem como o acréscimo de informações dos geossistemas locais.
\end{abstract}

Palavras-chave: Paisagens naturais, Geossistemas, Semiárido Brasileiro.

\begin{abstract}
The knowledge of the Brazilian semi-arid landscapes finds shelter in the geographical literature at least since the early 20th century. However, there is a need to clarify the limits of units and expand information about the natural organization of the landscapes. This study aimed to identify general aspects of the structure of semiarid geosystems of Brazil. A landscape map was prepared using geoprocessing and field data. Results were correlated with existing proposals and several landscape taxonomic models. The need for systematic surveys of the limits of the transitional geosystems and enclaves, as well as the additional information of local geosystems was evident.
\end{abstract}

Keywords: Natural landscapes, Geosystems, Brazilian semiarid.

\section{INTRODUÇÃO}

Em geografia física, o desenvolvimento de perspectivas integradas para o estudo das paisagens pode encontrar abrigo em Humboldt, quando o mesmo afirma que o objetivo último da geografia física é o de reconhecer a unidade na vasta diversidade de fenômenos (HUMBOLDT, 1858, p.43).

Contudo, apenas após o desenvolvimento das fotografias aéreas e da popularização da teoria dos sistemas (BERTALANFFY, 1950), é que os estudos sistemáticos e integrados da paisagem ganharam corpo. Isto acontece principalmente em função do contexto de exploração da potencialidade e limitações de uso do território, como nas colônias inglesas na África (BOURNE, 1931) ou nos territórios da Austrália (CHRISTIAN, STEWART, 1953) e da Rússia (SOLNETCEV, 2006). 
Neste contexto, o termo "geossistema" surgiu a partir de uma demanda de uniformização terminológica solicitada pela Sociedade de Geografia da então União Soviética em 1962 (SEMENOV; SNYTKO, 2013). Em 1963, Viktor Sochava propõe o termo geossistema como sendo "unidades geográfico-naturais de todas as categorias possíveis, indo do geossistema planetário ao geossistema elementar”. A justificativa para criação do termo, que seria similar em significado ao termo paisagem (como utilizado na antiga URSS), seria sua aplicação mais restrita à geografia física (SEMENOV; SNYTKO, 2013).

Em 1968, Georges Bertrand propôs o uso do termo geossistema referindo-se às paisagens de dimensões da IV e V ordens de grandeza. Contudo, num esforço de uniformização terminológica, o francês reconhece e aceita pouco tempo depois, que a proposta de Sochava é mais abrangente e adequada (BEROUTCHACHVILI; BERTRAND, 1978).

Ainda sobre a validade da proposta de Bertrand para outros contextos distintos do francês, destacamos a preocupação de Monteiro (1976, p.108) quando afirma que:

(...) Os conceitos de Bertrand, exemplificados em unidades observadas nos Pireneus, podem ser encontrados aqui no Brasil em unidades espaciais consideravelmente maiores, ultrapassando de muito as ordens de grandeza da escala taxonômica a que são referenciadas. Assim, ela pode configurar-se com grande margem de variação tanto ascendente quanto descendente. Um geossistema, definido em grande extensão, pressupõe geofácies maiores que muitos geossistemas contidos em outros espaços maiores.

Um exemplo é que o domínio cantábrico citado por Bertrand (1968) possui apenas 5.300 $\mathrm{km}^{2}$, enquanto o domínio das caatingas identificado por Ab'Saber (2003) supera os $850.000 \mathrm{~km}^{2}$. Com isso, há que se averiguar a validade da proposta de Bertrand tanto quanto investigar a organização hierárquica dos geossistemas brasileiros.

Neste sentido, destacamos que a proposta de Sochava inova pela assimilação da teoria dos sistemas aos estudos da paisagem, dando grande ênfase aos estudos estacionais. Desta feita, o estudo de geossistemas não se limita apenas à cartografia de paisagens e o reconhecimento de suas limitações e potencialidades (enfoque estrutural). Incluindo, também, o monitoramento da paisagem, equivalente à Pesquisa Ecológica de Longa Duração (Long Term Ecological Research) (enfoque dinâmico-funcional), além da pesquisa paleoambiental (enfoque evolutivo).

Um exemplo é o Método da Ordenação Complexa, proposto por Sochava (1978), que consiste em monitorar simultaneamente, diferentes atributos de geossistemas elementares, geralmente em 50 pontos estabelecidos em uma transecção com $1,5 \mathrm{~km}$ a $2 \mathrm{~km}$. Nesta transecção alguns dos atributos monitorados incluem: produtividade de biomassa, temperatura e umidade do ar e do solo, sazonalidade da pedobiota, fenologia, radiação total acima e abaixo do dossel, pH do solo e da serapilheira, percentual de carbono no solo, decomposição da serapilheira, ciclagem biogeoquímica, entre outros. 
Estes dados permitem definir o funcionamento dos geossistemas pelo conhecimento de seu balanço de energia, do balanço hídrico, bem como dos ciclos biogeoquímicos, da produtividade da biomassa e decomposição da serapilheira. Contudo, um primeiro passo no sentido do estudo de geossistemas é a sua cartografia.

Diferentes pesquisas têm sido desenvolvidas no semiárido brasileiro no sentido de conhecer melhor as áreas naturais (geossistemas) e apontar soluções para os problemas ambientais que os mesmos apresentam, sobretudo pela má gestão do uso da terra. O objetivo deste trabalho foi identificar aspectos da estrutura dos geossistemas do semiárido brasileiro.

\subsection{O que sabemos sobre os geossistemas do semiárido brasileiro?}

O semiárido brasileiro, cabe destacar que se trata de um dos ambientes menos estudados do Brasil (SANTOS et al., 2011), ao mesmo tempo em que se constitui na área com maior taxa de endemismos do mundo para as suas condições de clima e solo (HOEKSTRA et al., 2010). Além disto, é o semiárido mais populoso do mundo (AB'SABER, 1999) e possui o maior risco de alteração em relação às mudanças climáticas, em relação aos outros ambientes brasileiros (SIMÕES et al., 2010).

Assim, é fundamental o esforço no sentido de melhorar a qualidade ambiental da região. Neste sentido, a exploração detalhada de generalizações teóricas sobre os geossistemas, a exemplo daquela exposta em Ab'Saber (1984) aliada à inovação no uso de geotecnologias e bases de dados contemporâneas é indispensável ao desenvolvimento científico e subsídio aos instrumentos da Política Nacional do Meio Ambiente, a exemplo do ZEE.

No semiárido brasileiro, o reconhecimento de unidades dos sistemas ambientais já vem sendo realizado, em bases científicas, pelo menos desde Agamenon Magalhães (1921), Preston James (1952), Ab'Saber (1967, 1984, 2003) e Vasconcelos Sobrinho (1941, 1970). Outros trabalhos no mesmo sentido incluem os esforços de Isachenko e Shliapnikov (1989); Andrade (1998) e Silva et al. (2000) e Velloso, Sampaio e Pareyn (2002). Todos estes trouxeram grandes contribuições ao reconhecimento da estrutura dos geossistemas do semiárido brasileiro.

Vasconcelos Sobrinho (1970) divide o Nordeste em regiões naturais, utilizando a nomenclatura clássica: litoral, mata, agreste e sertão. De modo mais detalhado, Aziz Ab'Saber (1984) traz uma proposta de classificação dos principais geossistemas, geofácies e geótopos, considerado não apenas elementos típicos do domínio de natureza das caatingas, como também os enclaves, a exemplo dos brejos nordestinos.

Cartografando as paisagens do mundo, Isachenko e Shliapnikov (1989) apresentam as paisagens da América do Sul, incluindo a diversidade paisagística do semiárido com um nível de 
detalhamento cartográfico que só encontraria semelhante mais de dez anos depois, nos trabalhos de Silva et al. (2000) e Velloso, Sampaio e Pareyn (2002).

O trabalho de Silva et al. (2000), produto do Zoneamento Agroecológico do Nordeste (ZANE), é um marco da cartografia das paisagens no Brasil, trazendo grandes avanços em vários aspectos. Foi o primeiro a utilizar Sistemas de Informação Geográfica (SIG) para representar paisagens abrangendo áreas de tão vasta dimensão. As 20 grandes unidades de paisagem foram detalhadas em mais de 172 unidades geoambientais, num esforço notável.

Focando principalmente em aspectos pedológicos, geológicos e geomorfológicos, os mapas do ZANE receberam comentários no sentido de incluir dados da flora (GIULIETTI et al., 2002), seguindo a classificação de Andrade-Lima (1981). Além disso, algumas de suas unidades serviram de base para a delimitação das ecorregiões do bioma caatinga (VELLOSO; SAMPAIO; PAREYN, 2002).

Contudo, a pertinência dos limites das unidades do ZANE foi questionada por Cavalcanti (2010; 2013), sobretudo porque as unidades de paisagem, algumas de caráter morfoestrutural, foram obtidas por meio do agrupamento das classes de solos. O principal exemplo é o caso do Planalto da Borborema, cujos limites definidos no ZANE contrastam grosseiramente com os mapas geomorfológicos apresentados por diversos autores (AB'SABER, 1964; IBGE, 2006; CORREAA et al., 2010).

No presente momento, o conhecimento sobre os geossistemas do semiárido brasileiro permanece carente tanto em termos de refinamento cartográfico quanto em termos de funcionalidade geoecológica. Trata-se de uma necessidade de detalhar os limites das principais unidades, reconhecendo sua pertinência hierárquica e sua organização funcional do ponto de vista geossistêmico.

Neste sentido, a demanda pelo Zoneamento Ecológico-Econômico só tem a ganhar com um mapa de contornos mais precisos e cujas unidades sejam definidas, de fato, com base nas relações entre os diferentes componentes ambientais. Além disso, cabe salientar que os mapas mais atuais foram gerados sem a consideração de importantes bases de dados, a exemplo dos dados topográficos da Shuttle Radar Topography Mission (SRTM) e da carta geológica do Brasil ao milionésimo.

\section{MATERIAL E MÉTODOS}

Foi construído um modelo da distribuição dos geossistemas do semiárido brasileiro utilizando uma abordagem downscaling através de modelagem computacional, utilizando 
ferramentas de geoprocessamento e sensoriamento remoto. O intuito foi reconhecer um quadro de condicionamento da estrutura dos geossistemas regionais.

Para tanto, trabalhou-se com a ideia de limites naturais (ISACHENKO, 1973; 1991), este conceito sugere que os principais contrastes paisagísticos ocorrem associados a transições ou mudanças abruptas na configuração de fatores condicionantes, como as rochas, o relevo e o clima. O fluxograma a seguir (Fig. 1) sumariza as etapas da modelagem baseada na determinação de contrastes naturais.

No tocante à influência dos diferentes litotipos sobre a variabilidade das paisagens, sabe-se que no Semiárido Brasileiro, há diferença entre as caatingas que ocorrem nas áreas de rocha cristalina e aquelas de áreas sedimentares, particularmente as arenosas (CARDOSO; QUEIROZ, 2010). Além disso, estas áreas também se diferenciam pedologicamente e hidrologicamente, possuindo também formas de relevo distintas (CORRÊA, SOUZA, CAVALCANTI, 2014).

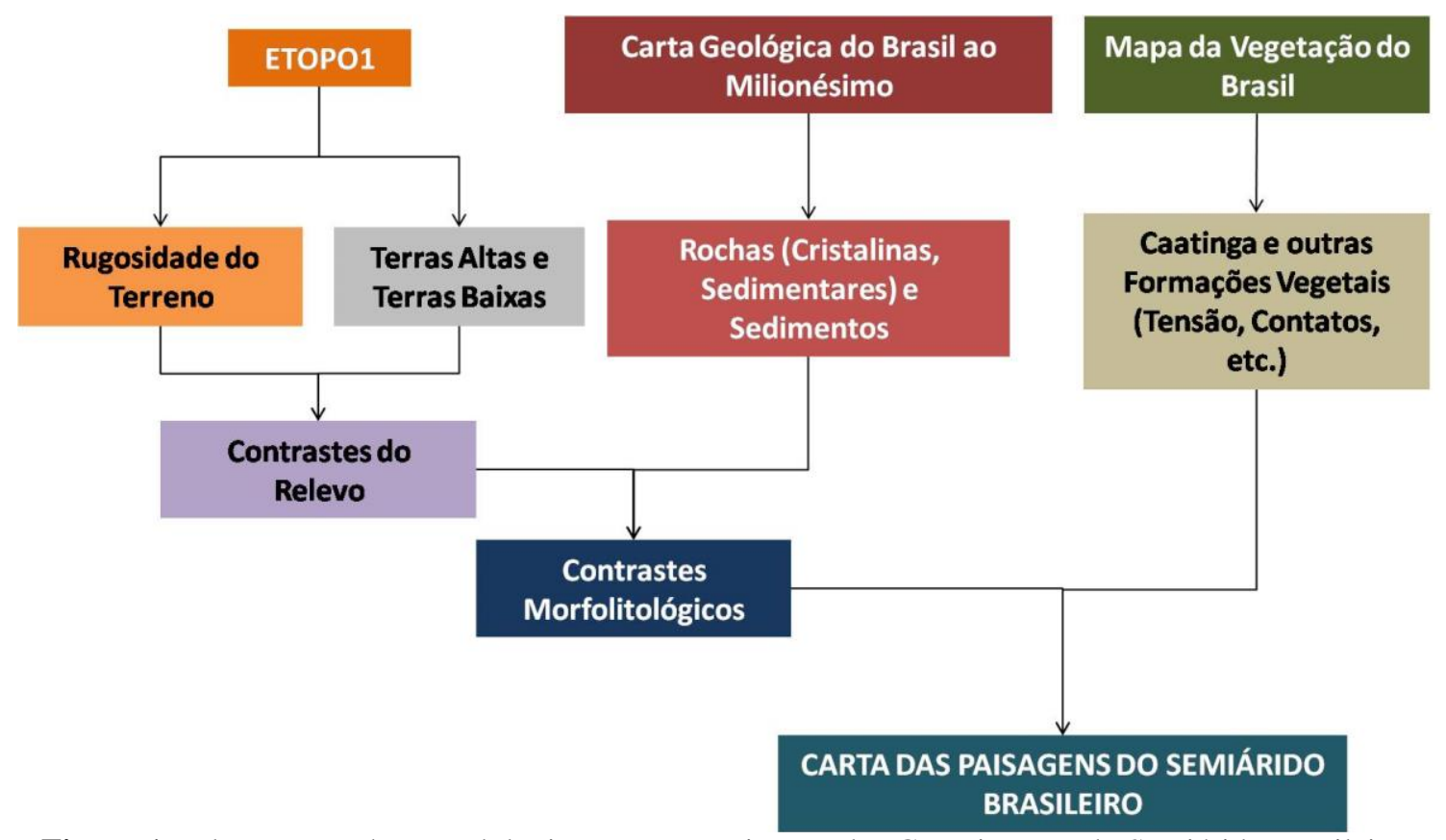

Figura 1 - Fluxograma da Metodologia para Determinação dos Geossistemas do Semiárido Brasileiro. Fonte: Elaborado pelo autor.

Para representar essa diferença, foi construído um modelo dos litotipos do Semiárido Brasileiro, baseando-se em 3 unidades principais: Rochas Cristalinas, Rochas Sedimentares, Sedimentos (Material Superficial). Este modelo foi construído com base nos arquivos digitais da Carta Geológica do Brasil ao Milionésimo, Folhas SA23, SA24, SB23, SB24, SB25, SC23, SC24, SC25, SD23, SD24, SE23 E SE24 (CPRM, 2014).

Para classificação dos litotipos, foram selecionadas todas as Classes de Rochas com ocorrência de Material Superficial; Sedimentar. As classes dos distintos arquivos das Folhas foram 
unidas utilizando a ferramenta de união de camadas do QGIS 2.14. O mesmo processo se repetiu para as rochas sedimentares e para as rochas cristalinas (ígneas e metamórficas).

Em relação ao relevo, compreende-se que o regime de circulação de substâncias químicas é um dos grandes fatores diferenciadores dos solos e que podem afetar padrões de abundância de plantas e mesmo a composição florística (CORRÊA; SOUZA; CAVALCANTI, 2014). Neste sentido, foi construído um modelo que diferenciasse duas categorias de relevo com influência nas condições geoquímicas dos solos: relevo suave e relevo acidentado.

Para representar essa diferença, foi utilizada modelagem numérica do terreno por meio do índice de rugosidade topográfica, que é obtido pelo desvio padrão da elevação. Foram utilizados dados do modelo global do relevo apresentado pelo projeto ETOPO1 (NOAA, 2014), com resolução espacial de 1 minuto de arco (aprox. 2,94 km) e abrangendo o recorte de coordenadas Lat. -20.46 e -0.25 e Long. -48.24 e $-33,47$.

Após a aplicação do índice de rugosidade, foi gerado um arquivo com o contorno dos valores de rugosidade em intervalos de 10. Em seguida, verificou-se qual valor de rugosidade representava melhor o contraste entre áreas de relevo suave e relevo acidentado. Foi escolhido o valor de rugosidade ' 10 ' para marcar esse limite.

Posteriormente, as linhas do contorno de rugosidade com valor 10 foram separadas em um novo arquivo e convertidas de linhas para polígonos, criando um arquivo vetorial das áreas de relevo acidentado. Em seguida, obtiveram-se as áreas de relevo suave pela diferença entre um arquivo de fundo (neste caso, utilizou-se o limite do semiárido brasileiro) e o arquivo do relevo acidentado. Por fim, os dois arquivos (suave e acidentado) foram unidos, gerando um arquivo dos contrastes topográficos.

Em relação ao efeito do clima sobre a configuração da paisagem, a altitude tem sido indicada como um fator de diferenciação em termos de variação dos regimes de pluviosidade, umidade do ar e temperaturas. Além disso, a composição florística é reconhecidamente variável em áreas elevadas do semiárido brasileiro (VASCONCELOS SOBRINHO, 1941; SANTOS, 2014, ARAÚJO, 1998, ARAÚJO et al. 2005; AB'SABER, 1984; 2003; PÔRTO; CABRAL; TABARELLI, 2004).

Uma vez que a vegetação é sensível aos aspectos climáticos, sejam estes influenciados pela altitude ou não, ela foi usada aqui como indicadora de variabilidade paisagística causada pelo clima. Para tanto, foi utilizado o contorno do mapa de vegetação do IBGE, recortado nos limites oficiais do Semiárido Brasileiro.

Com base neste arquivo, foi construído, por digitalização, um novo arquivo da vegetação diferenciando a caatinga das áreas de tensão ecológica, transição, cerrado, floresta estacional, mata seca e floresta ombrófila. Estas foram agrupadas numa única classe, permitindo a demarcação de 
áreas onde a caatinga divide espaço com outras formações e áreas onde a caatinga está concentrada (área core).

Além disso, todas as áreas elevadas acima de $600 \mathrm{~m}$ foram consideradas como terras altas, seguindo a indicação de Vasconcelos Sobrinho (1941). Para diferenciar as terras altas das terras baixas, foram extraídas curvas de nível dos dados do ETOPO1. Em seguida, as isolinhas de $600 \mathrm{~m}$ foram separadas em um único arquivo e convertidas de linhas para polígonos, gerando o arquivo de terras altas. Por fim, procedeu-se a união entre o arquivo de terras altas com o arquivo de relevo suave e acidentado. Este último arquivo passou a indicar terras altas acidentadas ou não e terras baixas, acidentadas ou não, chamamos este arquivo de 'contrastes de relevo'.

Posteriormente, o arquivo de contrastes de relevo foi unido ao arquivo dos litotipos, criando o arquivo 'morfolitológico' e permitindo diferenciar terras altas acidentadas ou não e estruturadas em rochas cristalinas, sedimentares ou sedimento inconsolado. O mesmo foi feito para as terras baixas. Ao final, construiu-se a carta das paisagens do semiárido brasileiro, sobrepondo os limites vegetacionais aos limites do relevo e litotipos.

Com o intuito de identificar padrões locais de geossistemas e investigar sua inserção hierárquica nos geossistemas regionais, foi elaborada uma carta de geossistemas na escala de 1:4000 com base nos dados de campo apresentados por Santos (2015). Estes dados incluem informações do relevo, dos solos e da vegetação da porção sudeste do município de Petrolina (Pernambuco). Seguiu-se os procedimentos descritos em Cavalcanti (2014). Por fim, os dados locais e regionais foram comparados com propostas e modelos taxonômicos de outros autores num quadro-síntese.

\section{RESULTADOS E DISCUSSÃO}

O modelo proposto (Fig. 2) consiste numa subdivisão do domínio do semiárido brasileiro em quatro grupos de paisagens principais: Terras Altas com Caatingas Hipoxerófilas; Terras Altas com Transição elou Enclaves Vegetacionais; Terras Baixas com Caatingas Hiperxerófilas e; Terras Baixas com Transição elou Enclaves Vegetacionais. Os seguintes subgrupos são identificados para as Terras Altas: em colinas sobre o cristalino; em colinas sobre sedimentos; em colinas sobre rochas sedimentares; em patamares escalonados sobre o cristalino; em patamares sobre rochas sedimentares; para as Terras Baixas, os seguintes subgrupos de paisagens figuram no mapa: em pedimentos; em inselbergs, colinas e piemontes cristalinos; em glacis; em dunas e colinas sobre sedimentos; em dunas, planícies, rampas e glacis de acumulação; em colinas sobre rochas sedimentares. 


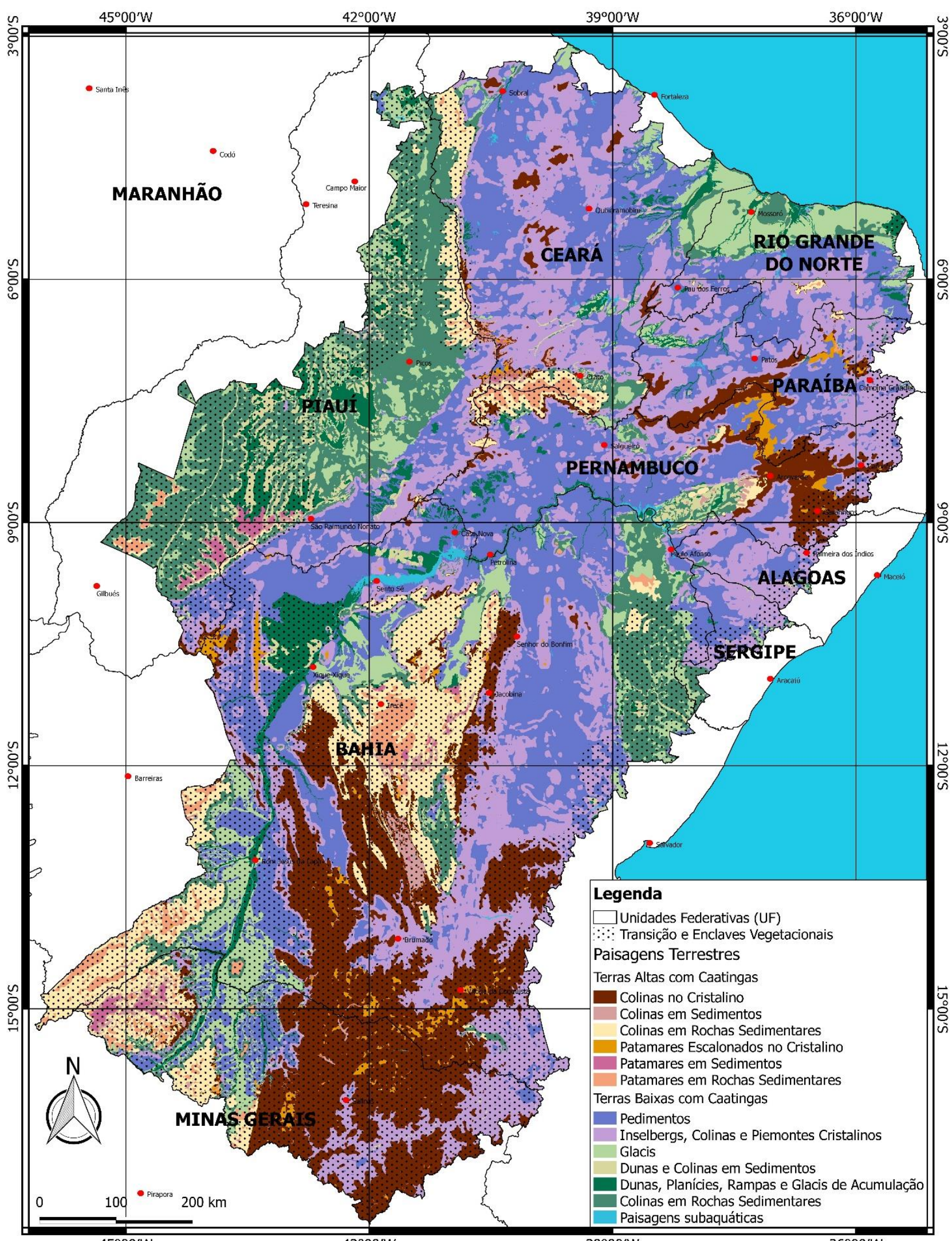

$45^{\circ} 00^{\prime} \mathrm{W} 42^{\circ} 00^{\prime} \mathrm{W}$

\section{Carta das Paisagens do Semiárido Brasileiro}

Figura 2 - Carta das Paisagens do Semiárido Brasileiro.

Fonte: Elaborado pelo autor. 
O mapa revela que a heterogeneidade paisagística do semiárido brasileiro é marcada por quatro grupos naturais e diversos subgrupos. Mais do que tudo, o mapa representa hipóteses sobre a estrutura, funcionamento e origem das paisagens regionais. O core semiárido, dominado pelas Terras Baixas com Caatingas Hiperxerófilas domina entre as latitudes de $3^{\circ}$ e $10^{\circ}$. As terras altas estruturadas em sedimentos e rochas sedimentares aparecem coincidindo com grande parte das transições e enclaves vegetacionais, com exceção do norte de Minas Gerais e das bordas do semiárido. A região de terras altas no nordeste oriental figura como dominante entre o grupo de Terras Altas com Caatingas Hipoxerófilas.

Comparando com outros modelos de representação das paisagens do semiárido brasileiro, a carta que ora é apresentada exibe um detalhamento e precisão maior no limite das unidades em relação àquele das Ecorregiões do Bioma Caatinga (VELLOSO, SAMPAIO, PAREYN, 2002) e também da proposta de Vasconcelos Sobrinho (1970) e Andrade (1998). Em relação à proposta de Ab'Saber (1984, 2003), James (1959), Walter (1986) e Isachneko e Shliapnikov (1989), a carta das paisagens do semiárido brasileiro avança em termos de apresentação e refinamento de limites de unidades e subunidades naturais. Em comparação com a proposta de Silva et al (2000), a carta inova por incluir todos os municípios do semiárido brasileiro, apresentando, contudo, uma precisão menor em relação à distribuição das unidades geoambientais.

Neste contexto, a área que selecionamos para a cartografia detalhada dos geossistemas está inserida no contexto dos inselbergs das terras baixas com caatingas (Fig. 3a e 3b). Observando este inselberg em detalhe, foi possível identificar diferentes geossistemas locais, dos quais destacamos os lajedos recobertos com bromélias (Encholirium spectabile) e o tálus dominado por angico de caroço (Anadenanthera collubrina) (Fig. 3c). Ainda no interior dos lajedos, destacamos um microgeossistema formado em fraturas nas rochas onde o solo e água aprisionados permitem a exploração por pequenas ervas terrestres (Fig. 3d).

Os resultados obtidos pelas abordagens regional e local permitiram identificar cinco categorias de geossistemas para o semiárido brasileiro, considerando localmente apenas os inselbergs de terras baixas com caatingas. Estas cinco categorias foram comparadas com a nomenclatura e com os critérios e taxonomias de autores distintos (Quadro 1).

A quantidade de geossistemas identificados ultrapassa a quantidade de níveis da proposta de Bertrand, mas apenas em termos de microambientes, o que significa que, considerando o caso observado, a proposta do francês tem aplicabilidade razoável para o detalhamento local do domínio das caatingas.

A proposta de Sochava inclui uma quantidade de categorias que não foram reveladas com os exemplos observados neste estudo. Isto significa que a proposta de Sochava possui categorias de 
sobra. Neste estudo não foram identificados correspondentes para: Classes de Geomas, Subclasses de Geomas, Subgrupos de Geomas e Classes de Fácies.

\section{A}
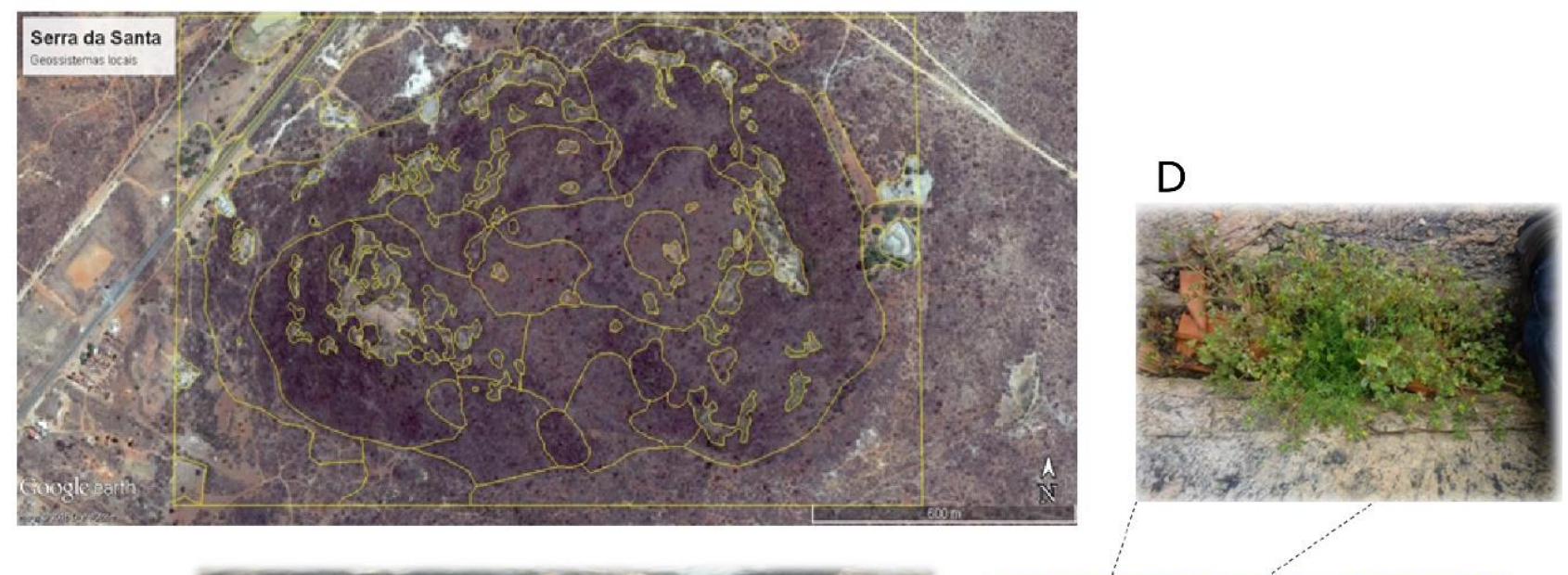

B
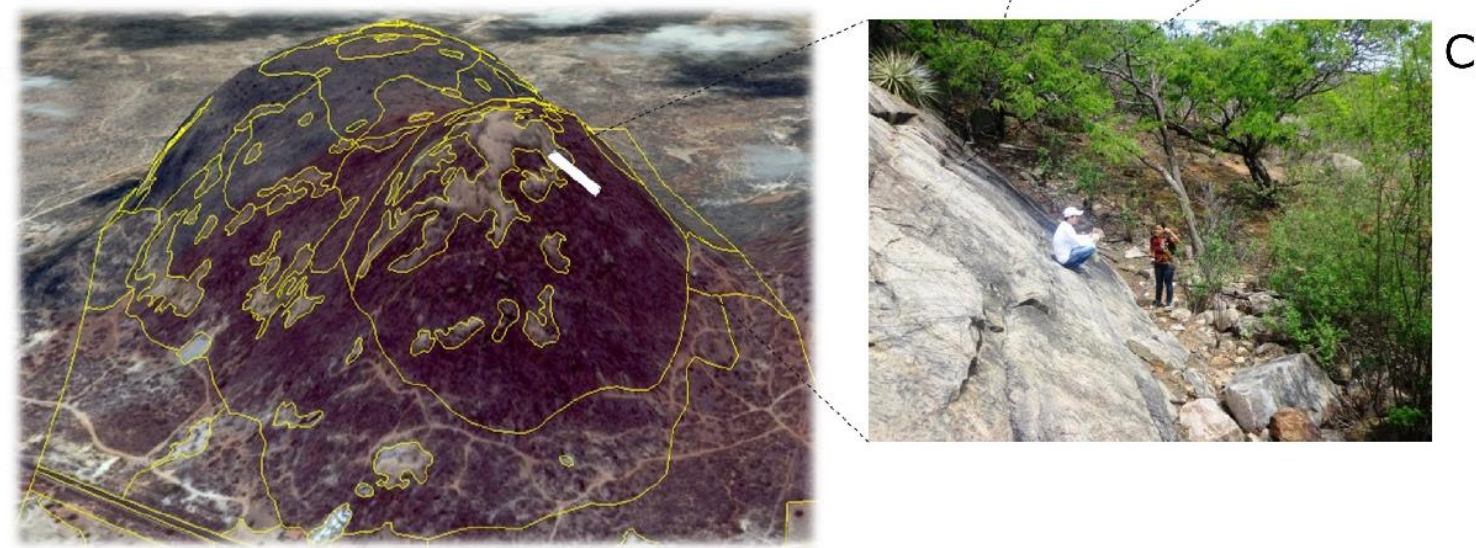

Figura 3. Distribuição dos Geossistemas Locais na Porção Sudeste de Petrolina, Pernambuco. A) Visão plana dos geossistemas locais mapeados sobrepostos à imagem de satélite; B) Visão em perfil dos geossistemas sobrepostos à imagem de satélite e modelo digital de elevação; C) Detalhe da transição entre geossistemas, lajedo com Encholirium (à esq.) e Tálus com Anadenanthera; D) Detalhe de fratura nas rochas com pequena mancha de solo e herbáceas (microgeossistema). Fontes: A, B e D, o autor. C, Ferreira Júnior, 2014.

Quadro 1. Comparação dos Geossistemas Observados com a Taxonomia de distintos autores.

\begin{tabular}{|c|c|c|c|c|c|c|c|}
\hline $\begin{array}{l}\text { Exemplo deste } \\
\text { estudo }\end{array}$ & $\begin{array}{c}\text { Isachenko e } \\
\text { Shliapnikov } \\
\text { (1989); } \\
\text { Isachenko } \\
\text { (1991) }\end{array}$ & $\begin{array}{c}\text { Sochava } \\
\text { (1978) }\end{array}$ & Walter (1986) & $\begin{array}{c}\text { Bertrand } \\
(1968 / 2009)\end{array}$ & Ab'Saber (2003) & ZANE & Ecorregiões \\
\hline Caatingas & $\begin{array}{l}\text { Subtipo de } \\
\text { Paisagem }\end{array}$ & $\begin{array}{c}\text { Tipos de } \\
\text { paisagens }\end{array}$ & Zonobioma & Domínio & $\begin{array}{l}\text { Domínio de } \\
\text { Natureza }\end{array}$ & - & Bioma \\
\hline Terras Baixas & $\begin{array}{l}\text { Grupo de } \\
\text { Paisagem }\end{array}$ & $\begin{array}{l}\text { Grupos de } \\
\text { Geomas }\end{array}$ & Bioma & Região Natural & Região Natural & $\begin{array}{l}\text { Unidade de } \\
\text { Paisagem }\end{array}$ & Ecorregião \\
\hline Inselbergs & Tipo de trato & Geomas & $\begin{array}{c}\text { Complexo } \\
\text { biogeocenótico } 1\end{array}$ & Geocomplexos & $\begin{array}{c}\text { Famílias de } \\
\text { Ecossistemas } 1\end{array}$ & $\begin{array}{c}\text { Unidade } \\
\text { Geoambiental }\end{array}$ & - \\
\hline $\begin{array}{c}\text { Encostas de } \\
\text { inselberg }\end{array}$ & Tipo de subtrato & $\begin{array}{l}\text { Grupos de } \\
\text { fácies }\end{array}$ & $\begin{array}{c}\text { Complexo } \\
\text { biogeocenótico } 2\end{array}$ & Geofácies & $\begin{array}{c}\text { Famílias de } \\
\text { Ecossistemas } 2\end{array}$ & Toposequência & - \\
\hline Lajedo & Tipo de fácies & Fácies & Biogeocenose & Geótopos & Minibiomas & - & - \\
\hline $\begin{array}{c}\text { Microambientes } \\
\text { de Fraturas }\end{array}$ & $\begin{array}{c}\text { Tipo de } \\
\text { microfácies }\end{array}$ & - & Sinúsia & - & Minibiomas & - & - \\
\hline
\end{tabular}

Fonte: Elaborado pelo autor. 
Propostas mais flexíveis como as de Walter e Ab'Saber, que preveem a possibilidade de vários níveis de complexos biogeocenóticos e famílias de ecossistemas, respectivamente, tem a vantagem de permitir a inclusão das categorias observadas. A desvantagem é que a existência de dois ou mais níveis de complexos biogeocenóticos/famílias de ecossistemas pode criar confusão na elaboração de legendas e mesmo na construção de textos explicativos.

O modelo taxonômico de Isachenko e Shliapnikov aplicado à América do Sul, bem como a proposta de Isachenko (1991) para classificação de paisagens naturais, apresentou boa correlação com as unidades que identificamos aqui. O grande problema em relação ao uso desta proposta, tal como a de Sochava, ainda é o abismo idiomático entre a língua russa e a portuguesa.

As propostas das Ecorregiões e do ZANE encontram boa correlação com as unidades identificadas neste trabalho no nível regional a que se propuseram. Destaca-se, contudo, os avanços apresentados aqui em termos de melhoria na precisão dos limites das unidades, bem como maior detalhamento da estrutura das áreas naturais.

\section{CONSIDERAÇÕES FINAIS}

Este trabalho permitiu tecer considerações sobre a organização natural das paisagens do semiárido brasileiro. Contudo, duas principais limitações são evidentes. A primeira delas é a falta de informações locais (neste trabalho abordou-se apenas um caso). A segunda é dada pelas limitações das bases de dados utilizadas para determinar os limites das unidades.

Neste sentido, a carta das paisagens do semiárido brasileiro não esgota o conhecimento da organização natural das paisagens, mas suscita questões posteriores de pesquisa que incluem:

- Ampliação dos conhecimentos sobre os grupos e subgrupos de paisagens;

- Identificação de táxons sub-regionais;

- "Amarração" dos subgrupos com as diferentes categorias de paisagens locais;

- Levantamento sistemático dos limites de transições e enclaves.

\section{Agradecimentos}

Ao CNPq pelo apoio ao projeto 472137/2014-0. Chamada MCTI/CNPQ/MEC/CAPES N²2/2014Ciências Humanas, Sociais e Sociais Aplicadas. 


\section{REFERÊNCIAS}

AB'SÁBER A.N. Domínios morfoclimáticos e províncias fitogeográficas do Brasil. Orientação, n.3, 1967.

AB'SABER, A.N. Ecossistemas Continentais. In: OLIVEIRA, E.M.; KACOWICZ, Z. (Coord.). Relatório da Qualidade do Meio Ambiente. Sinopse. Brasília - DF, SEMA, 1984. p.171-218.

AB'SABER, A. N. O relevo brasileiro e seus problemas. In: AZEVEDO. A. Brasil: a Terra e o Homem. vol.1, cap. III. São Paulo: Cia. Editora Nacional. 1964.

AB'SABER, A. N. Os domínios de natureza no Brasil: potencialidades paisagísticas. São Paulo: Ateliê Editorial, 2003. 159p.

AB'SABER, A.N. Sertões e Sertanejos: uma geografia humana sofrida. Estudos Avançados, v.13, n.36, 1999. p.7-59.

ANDRADE, L. A. Classificação Ecológica do Território Brasileiro Situado a Leste do Meridiano de $44^{\circ}$ Oeste e ao Norte do Paralelo de $16^{\circ}$ Sul - Uma abordagem climática. Tese de Doutorado (Ciência Florestal). Viçosa: Universidade Federal de Viçosa. 1999. 147p.

ANDRADE-LIMA, D. The Caatingas dominium. Revista Brasileira de Botânica, v.4, 1981. p.149-163.

ARAÚJO, F.S. Estudos Fitogeográficos do Carrasco no Nordeste do Brasil. Tese (Doutorado em Biologia Vegetal). Campinas: UNICAMP. 1998. Disponível em:

$<$ http://www.bibliotecadigital.unicamp.br/document/?code=vtls000133549> Acesso em: 23 set 2016.

ARAÚJO, F. S.; RODAL, M. J. N.; BARBOSA, M. R. V.; MARTINS, F. R. Repartição da flora lenhosa do domínio do bioma Caatinga. In: ARAÚJO, F. S.; RODAL, M. J. N.; BARBOSA, M. R. V. (Org.). Análise das variações da biodiversidade do bioma com apoio de sensoriamento remoto e sistema de informações geográficas para suporte de estratégias regionais de conservação. Brasília: Ministério do Meio Ambiente, 2005. p.16-35.

BERTALANFFY, L.V. An Outline of General System Theory. British Journal for the Philosophy of Science, v.1, 1950. p. 114-129. Disponível em:

<http://www.isnature.org/Events/2009/Summer/r/Bertalanffy1950-GST_Outline_SELECT.pdf>

Acesso em: 12 set 2016.

BEROUTCHACHVILI, N.L.; BERTRAND, G. Le Géosystème ou Système territorial naturel. Revue Géographique des Pyrénés et du sud-ouest. Toulose. 1978. p. 167-180.

BERTRAND, G. Paysage et géographie physique globale: esquisse méthodologique. Revue géographique des Pyrénées et sud-ouest, v. 39, fasc. 3, 1968. p. 249-272.

BOURNE, R. Regional Survey and its relation to stock taking of the agricultural and forest resources of the British Empire. Oxford Forestry Memoir. N. 13, 1931. 169p.

CARDOSO, D.B.O.S.; QUEIROZ, L.P. Caatinga no contexto de uma metacomunidade: evidências da Biogeografia, padrões filogenéticos e abundância em espécies de leguminosas. In: CARVALHO, 
C.J.B.; ALMEIDA, E.A.B. Biogeografia da América do Sul: Padrões \& Processos. São Paulo: ROCA. 2010. p.242-260.

CAVALCANTI, L.C.S. Cartografia de paisagens: fundamentos. São Paulo: Oficina de textos. 2014. 96p.

CAVALCANTI, L.C.S. Da descrição de áreas à teoria dos geossistemas: uma abordagem epistemológica sobre sínteses naturalistas. Tese (Doutorado em Geografia). Recife: UFPE. 2013. 218f. Disponível em: <http://repositorio.ufpe.br/handle/123456789/10661> Acesso em:23 set 2016.

CAVALCANTI, L. C. S. Geossistemas do Estado de Alagoas: uma contribuição aos estudos da natureza em geografia. Dissertação (Mestrado em Geografia). Recife: UFPE. 2010. 132p.

Disponível em:

<http://repositorio.ufpe.br/bitstream/handle/123456789/6581/arquivo674_1.pdf?sequence=1\&isAll owed $=\mathrm{y}>$ Acesso em 12 set 2016.

CHRISTIAN, C.S., STEWART, G.A. General report on survey of Katherine-Darwin Region, 1946. Melbourne: CSIRO. Land Research Series. No. 1. 1953. 177p. Disponível em: <http://www.publish.csiro.au/?act=view_file\&file_id=LRS01.pdf> Acesso em 12 set 2016.

CORRÊA, A.C.B.; SOUZA, J.O.P.; CAVALCANTI, L.C.S. Solos do Ambiente Semiárido Brasileiro: Erosão e Degradação a Partir de uma Perspectiva Geomorfológica. In: GUERRA, A.J.T.; JORGE, M.C.O. (Org.). Degradação dos Solos no Brasil. 1ed. Rio de Janeiro: Bertrand Brasil, 2014. p.127-169.

CORRÊA, A.C.B., TAVARES, B.A.C., MONTEIRO, K.A., CAVALCANTI, L.C.S., LIRA, D.R. Megageomorfologia e morfoestrutura do Planalto da Borborema. Revista do Instituto Geológico. São Paulo, v.31, n.1/2, 2010. p. 35-52.

CPRM. Serviço Geológico do Brasil. Carta Geológica do Brasil ao Milionésimo. Disponível em: <http://geobank.sa.cprm.gov.br/pls/publico/geobank.download.downloadVetoriais?p_webmap $=\mathrm{N \& p}$ usuario $=1>$ Acesso em 25 out 2014.

GIULIETTI, A.M.; HARLEY, R.M.; QUEIROZ, L.P.; BARBOSA, M.R.V.; BOCAGE NETA, A.L.; FIGUEIREDO, M.A. Espécies endêmicas da caatinga. In: SAMPAIO, E.V.B.; GIULIETTI, A.M.; VIRGÍNIO, J.; GAMARRA-ROJAS, C. (eds.). Vegetação e flora da caatinga. Associação plantas do nordeste - APNE \& Centro Nordestino de Informação sobre Plantas - CNIP, Recife. 2002. p.103-118.

HOEKSTRA, J., MOLNAR, J.L., JENNINGS, M., REVENGA, C., SPALDING, M.D., BOUCHER, T.M., ROBERTSON, J.C., HEIBEL, T.J., ELLISON, K. The Atlas of Global Conservation. Changes, Challenges, and Opportunities to Make a Difference. California: UC Press. 2010. 272p.

HUMBOLDT, A. Cosmos: a sketch of the physical description of the universe. v.1. 1858. Disponível em: <http://archive.org/details/cosmosasketchap02dallgoog> Acesso em 14 set 2013.

IBGE. Mapa de Unidades de Relevo do Brasil. 2ed. Brasília: IBGE. 2006. Disponível em: <ftp://geoftp.ibge.gov.br/informacoes_ambientais/geomorfologia/mapas/brasil/relevo_2006.pdf> Acesso em 23 set 2016. 
ISACHENKO, A.G. Ciência da Paisagem e Regionalização Físico-Geográfica. Moscou: Vyshaya Shkola. 1991. 370p. Em russo.

ISACHENKO, A.G.; SHLIAPNIKOV, A.A. Paisagens. Moscou: MISL. 1989. 504p. Em russo.

ISACHENKO, A.G. Principles of Landscape Science and Physical Geographic Regionalization. Melbourne. 1973.311p.

JAMES, P.E. Observations on the physical geography of Northeast Brazil. Annals of the Association of American Geographers v.42, n.2. 1952. p.153-176.

MAGALHÃES, A. O Nordeste Brasileiro. (tese apresentada ao Colégio Pernambucano para obtenção da cátedra de geografia). Recife. 1921.

MONTEIRO, C. A. F. Teoria e Clima Urbano. (tese de Livre Docência apresentada ao Depto de Geografia/FFLCH-USP). São Paulo, 1976.

NOAA. National Oceanic and Atmosphere Administration. ETOPO1 Global Relief Model. Disponível em: <http://maps.ngdc.noaa.gov/viewers/wcs-client/> Acesso em 25 out 2014.

PÔRTO, K. C.; CABRAL, J. J. P.; TABARELli, M. (Org.). Brejos de altitude em Pernambuco e Paraíba: história natural, ecologia e conservação. Brasília: Ministério do Meio Ambiente. 2004. $324 \mathrm{p}$.

SANTOS, J.C.; LEAL, I.R.; ALMEIDA-CORTEZ; J.S.; FERNANDES, G.W.; TABARELLI, M. Caatinga: the scientific negligence experienced by a dry tropical Forest. Tropical Conservation Science v.4, n.3, p.276-286, 2011.

SANTOS, K.P. Serra da Santa: Paisagem, Cartografia e Patrimônio. Monografia (Licenciatura em Geografia). Petrolina: UPE. 2015. 47p.

SANTOS, L.S. Estudo das alterações na cobertura vegetal ao longo de perfil topográfico, com ênfase em enclave de cerrado no Agreste Meridional de Pernambuco, Brasil. Dissertação (Mestrado em Geografia). Recife: UFPE. 2014.

SILVA, F.B.R.; RICHÉ, G.R.; TONNEAU, J.P.; SOUZA NETO, N.C.; BRITO, L.T.L.; CORREIA, R.C.; CAVALCANTI, A.C.; SILVA, F.H.B.B.; SILVA, A.B.; ARAÚJO FILHO, J.C.; LEITE, A.P. Zoneamento Agroecológico do Nordeste: diagnóstico e prognóstico. Recife: Embrapa Solos Escritório Regional de Pesquisa e Desenvolvimento Nordeste ERP/NE; Petrolina: Embrapa Semi-Árido, 2000. (Embrapa Solos, Documentos, 14). 1 CD ROM.

SILVA, F.B.R., SANTOS, J.C.P., SILVA, A.B., CAVALCANTI, A.C., SILVA, F.H.B.B., BURGOS, N., PARAHYBA, R.B.V., OLIVEIRA NETO, M.B., SOUZA NETO, N.C., ARAÚJO FILHO, J.C., LOPES, O.F., LUZ, L.R.Q.P., LEITE, A.P., SOUZA, L.G.M.C., SILVA, C.P., VAREJÃO-SILVA, M.A., BARROS, A.H.C. Zoneamento Agroecológico do Estado de Pernambuco. Recife: Embrapa Solos - Unidade de Execução de Pesquisa e Desenvolvimento UEP Recife; Governo do Estado de Pernambuco (Secretaria de Produção Rural e Reforma Agrária), 2001. CD-ROM.- (Embrapa Solos. Documentos; no. 35).

SIMÕES, A. F. et al. Enhancing adaptive capacity to climate change: the case of smallholder farmers in the Brazilian semi-arid region. Environmental Science \& Policy, v.13, p.801-8, 2010. 
SEMENOV, Yu. M.; SNYTKO, V.A. The 50th Anniversary of the Appearance of V. B. Sochava's First Article on the Geosystem. Geography and Natural Resources, v. 34, n.3. 2013. p.5-8.

SOCHAVA, V.B. Introdução à Teoria dos Geossistemas. Novosibirsk: Nauka, 1978. 320p. Em russo.

SOLNETCEV, N.A. The natural geographic landscape and some of its general rules. In: WIENS, J.A.; MOSS, M.R.; TURNER, M.G.; MLADENOFF, D.J. Foundation papers in Landscape Ecology. Columbia: Columbia University Press. 2006. p.19-27.

VASCONCELOS SOBRINHO, J. As regiões naturais de Pernambuco. Arquivos do Instituto de Pesquisas Agronômicas, n.3. 1941. p.25-32.

VASCONCELOS SOBRINHO, J. As regiões naturais do Nordeste: o meio e a civilização. Recife: Conselho do Desenvolvimento de Pernambuco. 1970. 441p.

VELLOSO, A.L.; SAMPAIO, E.V.S.B.; PAREYN, F.G.C. (eds.). Ecorregiões: Propostas para o bioma Caatinga. PNE-Associação Plantas do Nordeste; Instituto de Conservação Ambiental, The Nature Conservancy do Brasil, 2002, 76p.

Trabalho enviado em 02/11/2016

Trabalho aceito em 05/12/2016 